\title{
PERBANDINGAN UNDANG-UNDANG NOMOR 42 TAHUN 1999 TENTANG JAMINAN FIDUSIA DENGAN FATWA NOMOR 68/DSN-MUI/III/2008 TENTANG RAHN TASJILY
}

\author{
Witra Yosi \\ IAINBukittinggi,witra_yosi@gmail.com \\ Aidil Alfin \\ LAINBukittinggi, aidil_alfin@gmail.com \\ Basri Naáli \\ IAINBukittinggi, basri_akif@gmail.com
}

\begin{abstract}
This article discusses the substance of fiduciary guarantees according to Law Number 42 of 1999 concerning fiduciary guarantees with the substance rabn tasjily according to fatwa Number 68 / DSNMUI / III / 2008. In addition, it is also to find out the legal comparison between fiduciary guarantees according to Law Number 42 Year 1999 and rabn tasjily according to fatwa Number 68 / DSNMUI / III / 2008. The method used in this research is descriptive comparative analysis. Namely by comparing the substance of fiduciary guarantees according to Law Number 42 of 1999 with rahn tasjily according to DSN Fatwa Number 68 of 2008 as well as the similarities and differences between the two. The conclusion of this research is that the substance of the fiduciary guarantee according to Law No. 42 of 1999 is an agreement in which the debtor binds his agreement to the creditor for the accounts receivable debt which makes proof of ownership of an object to be used as collateral accompanied by an interest. While the substance of rahn tasjily according to fatwa Number 68 / DSN-MUI / III / 2008, namely the rabin binding agreement to the murtabin by using the qardh agreement (accounts receivable debt) accompanied by a collateral / collateral in which the collateral remains in control (utilization) rabin and proof of ownership submitted to the murtabin and ijarah rates in exchange for the cost of maintaining proof of ownership of the collateral. The legal comparison between fiduciary guarantees according to Law Number 42 of 1999 and rahn tasjily according to fatwa Number 68 / DSN-MUI / III / 2008 has similarities in the status of the collateral, the form of the agreement, subject, termination or deletion of the agreement and the method of execution of the object be a collateral object. While the difference lies in the maintenance of objects that are used as collateral for debt, in terms of binding guarantees, in terms of cancellation or transfer of rights by one party, in terms of the transfer of ownership rights and in terms of the mechanism of practice.
\end{abstract}

Keywords: Law Number 42 of 1999, Fiduciary Guarantee, DSN Fatwa Number 68 of 2008, Rahn Tasjily.

\begin{abstract}
Abstrak
Artikel ini membahas, substansi jaminan fidusia menurut Undang-Undang Nomor 42 Tahun 1999 tentang jaminan fidusia dengan substansi rahn tasjily menurut fatwa Nomor 68/DSNMUI/III/2008. Selain itu juga untuk mengetabui perbandingan bukum antara jaminan fidusia menurut Undang-Undang Nomor 42 Tabun 1999 dengan rahn tasjily menurut fatwa Nomor 68/DSN-MUI/III/2008. Metode yang digunakan dalam penalitian ini adalab deskriptif analisis
\end{abstract}


komparatif. Yaitu dengan membandingkan substansi jaminan fidusia menurut Undang-Undang Nomor 42 Tabun 1999 dengan rahn tasjily menurut Fatwa DSN Nomor 68 Tabun 2008 serta persamaan dan perbedaan di antara keduanya. Kesimpulan dari penelitian ini yaitu substansi jaminan fidusia menurut Undang-Undang No 42 Tabun 1999 adalah merupakan perjanjian di mana pihak debitur mengikatkan perjanjiannya kepada pibak kreditur atas butang piutang yang menjadikan bukti kepemilikan atas suatu benda untuk dijadikan sebagai jaminan dengan disertai adanya suatu bunga. Sedangkan substansi rahn tasjily menurut fatwa Nomor 68/DSN-MUI/III/2008 yaitu pibak rabin mengikatkan perjanjiannya kepada pibak murtabin dengan menggunakan akad qardh (butang piutang) yang disertai dengan sebuah agunan/ jaminan yang mana barang jaminan tersebut tetap berada dalam penguasaan (pemanfaatan) rabin dan buk.ti kepemilikeannya diserabkan kepada pihak murtahin serta tarif ijarah sebagai ganti biaya pemeliharaan bukti kepemilikan atas benda jaminan tersebut. Perbandingan bukum antara jaminan fidusia menurut Undang-Undang Nomor 42 Tabun 1999 dengan rabn tasjily menurut fatwa Nomor 68/DSN-MUI/III/2008 mempunyai persamaan pada status barang jaminannya, bentuk perjanjiannya, subjeknya, berakbir atau hapusnya perjanjian dan cara eksekusi atas benda yang menjadi objek jaminan. Sedangkan perbedaannya terletak pada pemelibaraan benda yang dijadikan jaminan atas butang, dari segi pengikatan jaminan, dari segi pembatalan atau pengaliban bak oleh salah satu pibak, dari segi hal perpindahan bak kepemilikan dan dari segi hal mekanisme praktiknya.

Kata Kunci: Undang-Undang Nomor 42 Tahun 1999, Jaminan Fidusia, Fatwa DSN Nomor 68 Tahun 2008, Rahn Tasjily.

\section{PENDAHULUAN}

Seiring dengan meningkatnya pembangunan ekonomi dan kebutuhan semakin banyak yang sebagian besar dana yang diperlukan untuk memenuhi kebutuhan hidup tersebut dapat diperoleh melalui kegiatan pinjam meminjam. Dalam kegiatan pinjam-meminjam terdapat produk yang dapat digunakan oleh masyarakat dalam bentuk penjaminan barang guna mendapatkan pembiayaan, diantaranya yaitu jaminan fidusia dan rahn. ${ }^{1}$

Pada awalnya perkembangan lembaga fidusia di Indonesia belum terkenal. Setelah dikeluarkannya Undang-Undang Nomor 42 Tahun 1999 tentang jaminan fidusia, lembaga fidusia mulai terkenal dan berkembang pesat di Indonesia. Yang dimaksud dengan Jaminan fidusia adalah hak jaminan atas benda bergerak baik yang berwujud

1 "KEDUDUKAN GADAI SYARIAH (RAHN) DALAM SISTEM HUKUM JAMINAN INDONESIA | Setyo | Jurnal Dinamika Hukum," accessed August 23, 2019, http://dinamikahukum.fh.unsoed.ac.id/index.php/JDH/artic le/view/133. maupun tidak berwujud dan benda tidak bergerak khususnya bangunan yang tidak dibebani hak tanggungan sebagaimana dimaksud dalam UndangUndang Nomor 4 Tahun 1996 tentang hak tanggungan yang tetap berada dalam penguasaan pemberi fidusia, sebagai agunan bagi pelunasan utang tertentu, yang memberikan kedudukan yang diutamakan kepada penerima fidusia terhadap kreditur lainnya. $^{2}$

Selain jaminan fidusia, akad rahn juga merupakan salah satu produk bentuk jasa pelayanan keuangan dalam bentuk pinjaman dengan menggadaikan barang sebagai jaminan hutang. Akad rahn bertujuan untuk memberikan kemudahan kepada masyarakat yang tidak mampu memenuhi kebutuhan hidupnya yang semakin bertambah, sehinnga masyarakat dapat meminjam

2 “AKIBAT HUKUM TERHADAP EKSEKUSI LELANG DENGAN TANPA ADANYA PUTUSAN PENGADILAN (Studi Di Pengadilan Agama Semarang) | Luthfi | LAW REFORM," accessed August 23, 2019, https://ejournal.undip.ac.id/index.php/lawreform/article/vie w/15872. 
uang kepada orang lain atau kepada lembaga pembiayaan. $^{3}$

Dikeluarkannya produk layanan jasa dengan akad rahn didasarkan pada sebuah alasan bahwa tidak semua orang mampu memenuhi kebutuhan hidupnya, dengan alasan penghasilan yang ia dapat kurang untuk memenuhi kebutuhan hidupnya yang semakin lama semakin bertambah, sehingga seseorang membutuhkan dana dengan cara berhutang dan dengan cara menggadaikan barang jaminannya di Pegadaian Syariah. Pada akhirnya Pegadaian Syariah memerlukan peraturan tentang fidusia syariah, maka dalam hal ini Majelis Ulama Indonesia mengeluarkan Fatwa yaitu Fatwa DSNMUI Nomor 68/DSN-MUI/III/2008 Tentang Rabn Tasjily sebagai alternatif fidusia dalam koridor syariah. $^{4}$

Rahn menurut Imam Abu Zakaria alAnshary dalam kitabnya Fathul Wahab adalah menjadikan benda yang bersifat harta benda sebagai kepercayaan dari suatu yang dapat dibayarkan dari harta benda tersebut bila utang tidak dibayar. ${ }^{5}$

Menurut fatwa Nomor 68/DSNMUI/III/2008 dinyatakan bahwa : rahn tasjily adalah jaminan dalam bentuk barang atas utang tetapi barang jaminan tersebut (marhun) tetap

3 "IMPLEMENTASI JAMINAN FIDUSIA DALAM PEMBERIAN KREDIT DI INDONESIA | PAPARANG | JURNAL LPPM BIDANG EKOSOSBUDKUM," accessed August 23, 2019, https://ejournal.unsrat.ac.id/index.php/lppmekososbudkum /article/view/7220.

4 "ANALISIS IMPLEMENTASI PEMBIAYAAN RAHN TASJILY TERHADAP KESESUAIANNYA DENGAN FATWA DSN-MUI NOMOR 68/DSNMUI/III/2008 (Studi Kasus Pada KSPPS BMT Mandiri Sejahtera Jawa Timur Cabang Balongpanggang) | J-MACC: Journal of Management and Accounting," accessed August 23, 2019, http://e-jurnal.unisda.ac.id/index.php/J$\mathrm{MACC} /$ article/view/752.

5 "ANALISIS FATWA DEWAN SYARIAH NASIONAL NOMOR: 92/DSN-MUI/IV/2014 TENTANG PEMBIAYAAN YANG DISERTAI RAHN | Ihtiar | An-Nisbah: Jurnal Ekonomi Syariah," accessed August 23, 2019, http://ejournal.iaintulungagung.ac.id/index.php/nisbah/article/view/274. berada dalam penguasaan (pemanfaatan) rabin dan bukti kepemilikannya diserahkan kepada murtabin. ${ }^{6}$

Berdasarkan unsur rabn tasjily yang telah dijelaskan di atas, sekilas terlihat mirip dengan jaminan fidusia, yaitu jaminan berdasarkan kepercayaan, yang objeknya tetap berada dalam penguasaan debitur, sedangkan bukti kepemilikannya diserahkan kepada kreditur. Sedangkan salah satu diantara perbedaannya, terletak pada benda yang dijaminkan. Pasal 1 ayat (2) Undang-Undang Nomor 42 Tahun 1999 Tentang Fidusia mengatur bahwa objek jaminan fidusia meliputi benda bergerak baik berwujud maupun tidak berwujud dan benda tidak bergerak khususnya bangunan yang tidak dapat dibebani oleh hak tanggungan. ${ }^{7}$ Yang dimaksud dengan benda bergerak baik yang berwujud maupun yang tidak berwujud disini adalah benda yang bukan merupakan objek gadai. Dalam praktik, objek fidusia adalah benda terdaftar. Rahn tasjily tidak membatasi mengenai pengertian objek barang jaminan, sehingga tanahpun dapat dijadikan sebagai objek jaminan. Selanjutnya bukti kepemilikan yang sah diserahkan kepada penerima jaminan (murtahin). Pemberi jaminan (rahin) tetap dapat menguasai dan memanfaatkan objek jaminan.

Untuk mengetahui lebih dalam persamaan dan perbedaan di antara konsep jaminan fidusia dengan rabn tasjily di atas perlu dilakukan penelitian intensif dalam kerangka penelitian hukum normatif,

6 "SINKRONISASI FATWA DSN-MUI NO: 68/DSN-MUI/III/2008 TENTANG RAHN TASJILY TERHADAP PASAL 5, PASAL 7, DAN PASAL 11 UNDANG-UNDANG NOMOR 42 TAHUN 1999 TENTANG JAMINAN FIDUSIA | Andisetya | Kumpulan Jurnal Mahasiswa Fakultas Hukum," accessed August 23, 2019,

http://hukum.studentjournal.ub.ac.id/index.php/hukum/arti cle/view/715.

7 "PELAKSANAAN PERJANJIAN KREDIT DENGAN JAMINAN SURAT KEPUTUSAN PENGANGKATAN PEGAWAI NEGERI SIPIL DI PT. BANK RAKYAT INDONESIA (PERSERO) CABANG SALATIGA - Diponegoro University | Institutional Repository (UNDIP-IR)," accessed August 23, 2019, http://eprints.undip.ac.id/17439/. 
maka dari itu penulis tertarik untuk melakukan penelitian terhadap substansi serta perbandingan antara Jaminan Fidusia (Undang-Undang Nomor 42 Tahun 1999) dengan Rahn Tasjily (Fatwa Nomor 68/DSN-MUI/III/2008).

\section{METODE PENELITIAN}

Penelitian ini termasuk jenis penelitian kepustakaan (Library Research), penelitian kepustakaan adalah pengumpulan data atau informasi dengan bantuan berbagai macam-macam materi yang terdapat di ruang perpustakaan. Dalam hal ini, penelitian dilakukan dengan cara membaca, menelaah dan mencatat bahan dari berbagai literatur yang berhubungan langsung dengan penelitian ini, serta literatur lain yang mempunyai hubungan dengan pemasalahan yang akan dikaji dalam penelitian ini mengenai jaminan fidusia dan rahn tasjily.

Penelitian ini bersifat deskriptif analisis komparatif, yang dimaksud dengan metode deskriptif adalah suatu metode dalam meneliti suatu objek yang bertujuan membuat deskripsi, gambaran atau lukisan secara sistematis dan objektif mengenai fakta-fakta, sifat-sifat, ciri-ciri serta hubungan antara unsur-unsur yang ada atau fenomena tertentu. Analisis yaitu suatu proses mengatur urutan data, mengorganisasikannya ke suatu pola, kategori, dan suatu uraian dasar yang kemudian melakukan pemahaman, penafsiran dan interpretasi data.

Metode komparatif adalah suatu metode yang membandingkan dua atau lebih tokoh atau aliran yang menelaah persamaan dan perbedaan mereka mengenai hakikat manusia, dunia, jiwa, politik.

Berdasarkan penjelasan diatas dapat disimpulkan bahwa yang dimaksud dengan deskriptif analisis komparatif yaitu metode yang menggambarkan atau melukiskan secara sistematis dan objektif mengenai fakta-fakta, sifat-sifat, ciriciri serta hubungan antara unsur-unsur yang ada kemudian melakukan uraian dasar dan melakukan pemahaman, penafsiran dan interpretasi data, serta membandingkannya. Dalam hal ini membandingkan substansi jaminan fidusia menurut Undang-Undang Nomor 42 Tahun 1999 dengan rahn tasjily menurut Fatwa DSN Nomor 68 Tahun 2008 serta persamaan dan perbedaan di antara keduanya.

\section{PERBANDINGAN UNDANG-UNDANG NOMOR 42 TAHUN 1999 TENTANG JAMINAN FIDUSIA DENGAN FATWA NOMOR 68/DSN-MUI/III/2008 TENTANG RAHN TASJILY}

Jaminan fidusia merupakan perjanjian ikutan dari suatu perjanjian pokok yang menimbulkan kewajiban bagi para pihak untuk memenuhi suatu prestasi. Untuk memenuhi suatu prestasi para pihak dalam perjanjian jaminan fidusia, para pihak harus memenuhi kewajibannya masing-masing. Agar tidak menimbulkan kerugian di antara salah satu pihak, dan agar terpenuhi prestasi di antara para pihak maka para pihak harus mendaftarkan jaminan fidusia untuk melindungi kepentingan para pihak, baik pihak kreditur maupun pihak debitur. Dan diharapkan juga, untuk memberantas debitur yang nakal terhadap kreditur. Misalnya: nakal dalam hal mengkhianati pihak kreditur, dengan cara menjual barang yang menjadi objek jaminan fidusia atau debitur melakukan fidusia ulang terhadap benda yang menjadi objek jaminan fidusia.

Jaminan fidusia wajib didaftarkan, sebagaimana kita telah mengenal berbagai asas yang terdapat di dalam hukum jaminan. Salah satunya yaitu asas publisitas yang merupakan suatu hal keharusan untuk memberikan info atau pengumuman kepada masyarakat mengenai status atas kepemilikan suatu benda yang dijadikan agunan dalam perjanjian jaminan fidusia. Jadi, dengan adanya asas publisitas ini pihak debitur diwajibkan 
untuk mendaftarkan jaminan fidusia kepada Kantor Pendataran fidusia. ${ }^{8}$

Jaminan fidusia dapat dikategorikan sebagai pembiayaan konsumen, hal ini dapat kita ketahui pengertiannya menurut Salinan Peraturan Ketua Badan Pengawas Pasar Modal dan Lembaga Keuangan Nomor : PER-03/BL/2007 Tentang Kegiatan Perusahaan Pembiayaan Berdasarkan Prinsip Syariah, yang mana sebagai berikut: "Pembiayaan konsumen (costumer finance) adalah kegiatan pembiayaan untuk pengadaan barang berdasarkan kebutuhsn konsumen dengan pembayaran secara angsuran sesuai dengan prinsip syariah".

Akad rahn merupakan salah satu produk bentuk jasa layanan keuangan dalam bentuk pinjaman dengan menggadaikan barang sebagai jaminan hutang. Akad rahn bertujuan untuk memberikan kemudahan kepada masyarakat yang tidak mampu memenuhi kebutuhan hidupnya yang semakin bertambah, sehingga masyarakat dapat meminjam uang kepada orang lain atau kepada lembaga pembiayaan.

Setiap produk jasa layanan syariah tidak terlepas dari Dewan Syariah Nasional Majelis Ulama Indonesia (DSN-MUI) yang mengeluarkan fatwa terhadap setiap produk yang ada dalam perbankan syariah/jasa layanan keuangan syariah, sehingga produk yang akan dikeluarkan oleh perbankan syariah atau jasa layanan keuangan syariah berlandaskan prinsip syariah. Salah satu produk layanan jasa keuangan syariah yaitu dengan akad rabn.

Dikeluarkan produk layanan jasa dengan akad rahn didasarkan pada sebuah alasan bahwa tidak semua orang mampu untuk memenuhi kebutuhan hidupnya, dengan alasan penghasilan

8 "AKIBAT HUKUM PENDAFTARAN JAMINAN FIDUSIA DALAM SISTEM ONLINE | Acta Comitas: Jurnal Hukum Kenotariatan," accessed August 23, 2019, https://ojs.unud.ac.id/index.php/ActaComitas/article/view/ 35014. hidupnya yang semakin lama semakin bertambah, sehingga seseorang membutuhkan dana dengan cara berhutang dan dengan menyerahkan agunan atau jaminan atas hutangnya tersebut. Atas alasan tersebut, DSN-MUI mengeluarkan fatwa terkait dengan akad rahn yaitu Fatwa Nomor 25/DSNMUI/III/2002 tentang rahn.Landasan hukum yang menjadi dasar dikeluarkannya fatwa tentang akad rahn yaitu hadis dari Abu Hurairah r.a bahwasanya Rasulullah SAW, bersabda:

Dari Abu Hurairah Radbiyallabu Anbu, ia berkata, "Rasulullab S.A.W bersabda,"Barang yang digadaikan tidak dipisabkan kepemilikannya dari pibak yang memilikinya yang telah menggadaikannya". (H.R Imam Asy-Syafi'i dan Ad-Daraquthni, ia berkata, "Sanad hadis ini hasan dan muttashil"

Dapat kita ambil pengertian dari hadis di atas yang menunjukkan bahwa produk layanan jasa dengan akad rahn diperbolehkan dengan prinsip syariah, dimana pihak rahin tetap menjadi pihak atas kepemilikan benda yang dijadikan jaminan hutang, bukan berarti jika pihak rahin tidak dapat melunasi hutangnya sampai waktu yang telah ditentukan pihak murtabin dapat memiliki barang yang dijadikan jaminan hutang rabin tersebut.

Selain Fatwa Nomor 25/DSNMUI/III/2002 tentang rahn yang memberikan pelayanan jasa dalam bentuk pinjaman yang menjadikan suatu benda sebagai jaminan hutangnya tersebut, yang dimaksud benda yang dijadikan jaminan tersebut yaitu harus diserahkan dalam bentuk fisik atau wujud dari benda tersebut. Dan benda yang dapat dijadikan jaminan harus berbentuk harta, harus memiliki nilai, milik sendiri artinya bukan kepemilikan orang lain, dan lain-lain. Ada pula produk jasa layanan keuangan syariah lainnya yaitu yang tidak lain dari jenis dari rahn, dimana benda yang dijadikan jaminan atas hutangnya bukan fisik dari benda tersebut, melainkan yang dijadikan jaminan berupa bukti 
kepemilikannya. Hal ini juga dapat meringankan bagi pihak rahin yang masih bisa menikmati benda yang dijadikan jaminan atas hutangnya, karena benda jaminannya tetap berada di rahin. Produk tersebut dinamakan rabn tasjily yang diatur dalam Fatwa Nomor 68/DSN-MUI/III/2008 tentang rahn tasjily. Pengertian rahn tasjily dapat diuraikan menurut Fatwa DSN-MUI sebagai berikut: "Rahn tasjily adalah jaminan dalam bentuk barang atas hutang tetapi barang jamiann tersebut (marbun) tetap berada dalam penguasaan (pemanfaatan) rahin dan bukti kepemilikannya diserahkan kepada murtabin".

Sebagaimana pembahasan dan penjelasan yang telah penulis paparkan di atas, konsep antara jaminan fidusia dengan rahn tasjiy ini di samping mempunyai persamaan juga mempunyai perbedaan. Jaminan fidusia dengan rahn tasjily ini tidak dapat berdiri sendiri, mereka ada dikarenakan perjanjian pokok yaitu hutang piutang. Oleh karena itu perjanjian ini tidak daopat berdiri sendiri tanpa adanya perjanjian pokok, yang dikenal juga dengan istilah accesoir (ikutan).

Rabn tasjily dan jaminan fidusia merupakan produk pembiayaan yang saat ini berkembang dengan pesat di tangah-tebgah kehidupan masyarakat, karena selain mempermudah masyarakat dalam memenuhi kehidupan baik perseorangan ataupun badan hukum. Kedua produk ini merupakan produk pembiayaan yang dapat diperoleh melalui kegiatan pinjam-meminjam dengan menaminkan suatu benda. Perlu diketahui bahwasanya rahn tasjily dengan jaminan fidusia ini yang dijaminkan adalah hak kepemilikan bendanya saja, sedangkan bendanya tetap berada dalam penguasaan pemiliknya. Dengan ketentuan bahwa bukti kepemilikan dari barang yang dijadikan jaminan itu ditahan oleh yang menerima jaminan sampai semua hutang dilunasi.

Fungsi dari barang jaminan itu sendiri adalah untuk memberikan hak dan kekuasaan untuk mendapatkan pelunasan dari agunan apabila debitur melakukan cidera janji, yaitu untuk membayar kembali hutangnya pada waktu yang telah ditetapkan dalam perjanjian. Di samping itu penerima fidusia (debitur) wajib mengajukan permohonan pendaftaran terhadap benda yang dijaminkan dengan jaminan fidusia ke kantor pendaftaran jaminan fidusia. Tujuan pendaftaran ini dimaksudkan untuk memberikan kepastian hukum kepda para pihak yang berkepentingan dan memberikan hak yang istimewa kepada si penerima fidusia untuk tetap menguasai benda yang menjadi objek jaminan fidusia berdasarkan kepercayaan.

Ketika bukti kepemilikan barang jaminan berada di tangan kreditur, sementara barang tersebut tetap berada pada debitur dan debitur memanfaatkan barang tersebut sebagaimana biasanya maka hal ini tidaklah masalah. Karena pada jaminan fidusia kreditur tetap mempunyai hak manfaat, sedangkan kreditur secara yuridis mempunyai hak milik sampai hutang tersebut dibayar lunas oleh debitur. Dalam hal ini, pada prinsipnya tidaklah bertentangan dengan konsep rahn tasjily, hanya saja di dalam Fatwa rahn tasjily ditekankan bahwa dengan beradanya bukti kepemilikan suatu barang di tangan murtahin itu berarti tidak terjadinya perpindahan kepemilikan dari rahin kepada murtahin. Sebagaimana dijelaskan dalam sebuah hadis yang diriwayatkan oleh AlSyafi'i, Al-Daruqhutni dan Ibnu Majah. Dari Abu Hurairah, Nabi SAW bersabda:

Tidak terlepas kepemilikan barang gadai dari pemilik yang menggadaikannya. Ia memperoleh manfaat dan menanggung resikonya." (HR. AlSyafi'i, Al-Daruqhutni dan Ibnu Majah)

Salah satu perbedaan yang sangat kontras antara jaminan fidusia dengan rahn tasjily adalah dari segi mekanisme prakteknya. Jaminan fidusia di perbankan konvensional dipraktekkan dengan cara menganut sistem bunga dalam hal pengambilan keuntungan dari pihak debitur. Di dalam pandangan Islam ditegaskan bahwa bunga bank 
sama dengan riba, yakni dilarang. Larangan itu dinyatakan sangat jelas di dalam beberapa ayat AlQur'an, yaitu salah satunya di dalam Surah AlBaqarah ayat 275.

Artinya: Orang-orang yang Makan (mengambil) riba tidak dapat berdiri melainkan seperti berdirinya orang yang kemasukan syaitan lantaran (tekanan) penyakit gila. Keadaan mereka yang demikian itu, adalah disebabkan mereka berkata (berpendapat), Sesunggubnya jual beli itu sama dengan riba, Padahal Allah telah menghalalkan jual beli dan mengharamkan riba. orang-orang yang telah sampai kepadanya larangan dari Tubannya, lalu terus berhenti (dari mengambil riba), Maka baginya apa yang telah diambilnya dabulu (sebelum datang larangan); dan urusannya (terserah) kepada Allah. orang yang kembali (mengambil riba), Maka orang itu adalah penghuni-penghuni neraka; mereka kekal di dalamnya.

Untuk menghindari hal tersebut, rahn tasjily dalam mekanisme prakteknya di perbankan syariah menggunakan akad tambahan yaitu akad ijarah guna memperoleh margin. Akad ijarah ini dibebankan kepada rahin sebagai biaya pemeliharaan dan penyimpanan marhun (berupa bukti sah kepemilikan atau sertifikat) atau biasa juga disebut dengan save deposit box. Besaran biaya pemeliharaan dan penyimpanan marhun tidak boleh dikaitkan dengan jumlah pinjaman yang diberikan. Cara ini dipraktekkan dalam perbankan syariah agar terhindar dari riba guna memperoleh margin.

Jadi, apabila dicermati mengenai konsep rahn tasjily yang ada di dalam Fatwa DSN No.68/DSN-MUI/III Tahun 2008, bisa dikatakan bahwa sebenarnya rabn tasjily ini adalah jaminan fidusia yang disyariahkan. Mengapa dikatakan demikian?. Hal ini di karenakan konsep rabn tasjily yang ada di dalam Fatwa DSN No.68/DSNMUI/III Tahun 2008 tersebut sangat mirip dengan konsep jaminan fidusia yang ada di dalam UndangUndang No 42 Tahun 1999 meskipun tidak seutuhnya sama. Salah satu diantara perbedaan konsep itu terlihat dalam hal mekanisme prakteknya di lembaga perbankan.

Meskipun demikian, jaminan fidusia ini bisa juga di terapkan di lembaga perbankan syariah dengan cara menghilangkan sistem bunga dan menggantinya dengan akad ijarah terhadap penyewaan save deposit box dalam memperoleh margin atau keuntungan. Karena, pengaturan jaminan fidusia di dalam Undang-Undang No 41 Tahun 1999 ini lebih rinci dan kompleks ketimbang rahn tasjily yang ada di dalam Fatwa DSN No.68/DSN-MUI/III Tahun 2008. Mulai dari objek benda yang bisa dijaminkan, kewajiban dan tata cara mengenai pendaftaran objek yang dijaminkan hingga cara eksekusi benda yang dijaminkan apabila salah satu pihak wanprestasi diatur secara rinci dan jelas di dalam UUJF. Jadi, sebenarnya jaminan fidusia juga bisa dipakai di lembaga perbankan syariah dengan catatan harus berada dan sesuai dengan koridor syariah.

\section{KESIMPULAN}

Berdasarkan pembahasan dan hasil penelitian yang telah penulis kemukakan pada babbab sebelumnya, maka penulis menarik kesimpulan bahwa substansi jaminan fidusia menurut UndangUndang Nomor 42 Tahun 1999 yaitu jaminan fidusia merupakan perjanjian di mana pihak debitur mengikatkan perjanjiannya kepada pihak kreditur atas hutang piutang yang menjadikan bukti kepemilikan atas suatu benda untuk dijadikan jaminan atas hutangnya tersebut dengan disertai adanya suatu bunga. Sedangkan substansi rahn tasjily menurut fatwa Nomor 68/DSN-MUI/III/2008 yaitu pihak rabin mengikatkan perjanjian kepada pihak murtabin, yang dinamakan dengan perjanjian rahn tasjily dengan menggunakan akad qard (butang piutang) yang disertai dengan sebuah agunan / jaminan berupa barang atas hutang yang barang jaminan tersebut tetap berada dalam penguasaan (pemanfaatan) rahin dan bukti kepemilikannya diserahkan kepada pihak murtahin serta tarif ijarah 
sebagai ganti biaya pemeliharaan bukti kepemilikan atas benda jaminan tersebut. Perbandingan hukum antara jaminan fidusia menurut Undang-Undang Nomor 42 Tahun 1999 dengan rabn tasjily menurut fatwa Nomor 68/DSN-MUI/III/2008 mempunyai persamaan pada status barang jaminannya, bentuk perjanjiannya, subjeknya, berakhir atau hapusnya perjanjian dan Cara eksekusi atas benda yang menjadi objek jaminan. Sedangkan perbedaan antara jaminan fidusia dengan rabn tasjily terletak pada pemeliharaan benda yang dijadikan jaminan atas hutang, dari segi pengikatan jaminan, dari segi pembatalan atau pengalihan hak oleh salah satu pihak, dari segi hal perpindahan hak kepemilikan dan dari segi hal mekanisme praktiknya.

\section{DAFTAR KEPUSTAKAAN}

"AKIBAT HUKUM PENDAFTARAN JAMINAN FIDUSIA DALAM SISTEM ONLINE | Acta Comitas : Jurnal Hukum Kenotariatan.” Accessed August 23, 2019. https://ojs.unud.ac.id/index.php/ActaCom itas/article/view/35014.

"AKIBAT HUKUM TERHADAP EKSEKUSI LELANG DENGAN TANPA ADANYA PUTUSAN PENGADILAN (Studi Di Pengadilan Agama Semarang) | Luthfi | LAW REFORM." Accessed August 23, 2019.

https:/ / ejournal.undip.ac.id/index.php/law reform/article/view/15872.

"ANALISIS FATWA DEWAN SYARIAH NASIONAL NOMOR: 92/DSNMUI/IV/2014 TENTANG PEMBIAYAAN YANG DISERTAI RAHN | Ihtiar | An-Nisbah: Jurnal Ekonomi Syariah." Accessed August 23, $2019 . \quad$ http://ejournal.iaintulungagung.ac.id/index.php/nisbah/article /view/274.

"ANALISIS IMPLEMENTASI PEMBIAYAAN RAHN TASJILY TERHADAP KESESUAIANNYA DENGAN FATWA DSN-MUI NOMOR 68/DSNMUI/III/2008 (Studi Kasus Pada KSPPS
BMT Mandiri Sejahtera Jawa Timur Cabang Balongpanggang) | J-MACC: Journal of Management and Accounting." Accessed August 23, 2019. http://ejurnal.unisda.ac.id/index.php/JMACC/article/view/752.

"IMPLEMENTASI JAMINAN FIDUSIA DALAM PEMBERIAN KREDIT DI INDONESIA | PAPARANG | JURNAL LPPM BIDANG EKOSOSBUDKUM." Accessed August 23, 2019. https://ejournal.unsrat.ac.id/index.php/lpp mekososbudkum/article/view/7220.

"KEDUDUKAN GADAI SYARIAH (RAHN) DALAM SISTEM HUKUM JAMINAN INDONESIA | Setyo | Jurnal Dinamika Hukum." Accessed August 23, 2019. http://dinamikahukum.fh.unsoed.ac.id/ind ex.php/JDH/article/view/133.

"PELAKSANAAN PERJANJIAN KREDIT DENGAN JAMINAN SURAT KEPUTUSAN PENGANGKATAN PEGAWAI NEGERI SIPIL DI PT. BANK RAKYAT INDONESIA (PERSERO) CABANG SALATIGA Diponegoro University | Institutional Repository (UNDIP-IR)." Accessed August 23, 2019. http://eprints.undip.ac.id/17439/.

"SINKRONISASI FATWA DSN-MUI NO: 68/DSN-MUI/III/2008 TENTANG RAHN TASJILY TERHADAP PASAL 5, PASAL 7, DAN PASAL 11 UNDANGUNDANG NOMOR 42 TAHUN 1999 TENTANG JAMINAN FIDUSIA | Andisetya | Kumpulan Jurnal Mahasiswa Fakultas Hukum." Accessed August 23, 2019.

http://hukum.studentjournal.ub.ac.id/inde x.php/hukum/article/view/715. 